\title{
Chapter 11 \\ The Role of Informal Childcare in Mothers' \\ Experiences of Care and Employment: \\ A Qualitative Lifecourse Analysis
}

\author{
Michelle Brady
}

\section{Introduction}

This chapter argues that single mothers who use mixed childcare (concurrent use of formal and informal childcare) have much greater success in entering and sustaining employment compared to single mothers who have a formal-only childcare package (i.e. rely entirely on formal childcare), or an informal-only package. To date the literature on single parents and employment has largely ignored the widespread use of mixed childcare amongst families. While this omission is important for all family types, it is a particular problem for the literature on single mothers because my prior research has found that single mothers who use mixed childcare on average working significantly longer hours compared to mothers who use other childcare packages, after controlling for a range of demographic factors and hours of childcare used (Brady and Perales 2016). ${ }^{1}$ Further, descriptive statistics show that Australian single mothers who use mixed childcare packages have higher employment rates compared to mothers who use other childcare packages (Baxter et al. 2007).

Drawing on a lifecourse and caringscapes conceptual framework and applying them to a qualitative longitudinal (QL) study with 30 Australian single mothers in receipt of single rate Parenting Payment (PPS) (an income support payment) and with at least one child aged less than 7 years, the chapter argues that the observed correlation between hours of employment and childcare package exists because, for most single parents, the childcare offered by formal providers is insufficiently

\footnotetext{
${ }^{1}$ Partnered mothers who use mixed childcare also work significantly longer hours compared to mothers who use only formal care or only informal care. However, for "for partnered mothers mixed childcare increases employment hours by maximizing the hours of childcare available to them" whereas this is not the case for single mothers (Brady and Perales 2016, p. 1).

M. Brady $(\triangle)$

School of Social Science, University of Queensland, St Lucia, QLD, Australia

School of Public Administration, University of Victoria, Victoria, BC, Canada e-mail: m.brady2@uq.edu.au
}

(C) The Author(s) 2018

L. Bernardi, D. Mortelmans (eds.), Lone Parenthood in the Life Course, Life

Course Research and Social Policies 8, DOI 10.1007/978-3-319-63295-7_11 
flexible on a day- to-day basis and does not adequately respond to changes that occur across the children's and mothers' lifecourses. Furthermore, informal-only care is unreliable over the longer term. Mixed childcare packages typically provide mothers with access to the longer hours of care usually associated with formal care, but also access to the flexibility usually associated with informal care. This flexibility afforded by the informal care allows these single mothers to adapt to changes across the lifecourse.

The degree to which the flexibility of informal carers is necessary is dependent upon the childcare and employment policy context. In Australia formal childcare is inflexible in three distinct ways. Firstly, formal childcare is generally only offered during standard working hours and very little formal care is offered in the evenings or on weekends. These restricted childcare hours cause problems for the many single mothers who work non-standard hours. Secondly, formal childcare requires families to choose fixed days of care and generally does not allow families to change their days of care from week to week. This requirement to choose fixed days of care generates problems for employed mothers who have rotating shifts. Finally, formal care is inflexible in terms of offering sharply age segmented care. For example, some providers only offer care for children under 2.5 years whilst others do not offer a kindergarten program for 4 year olds. The result is that parents commonly need to change providers multiple times in the first decade of a child's life, and once their child starts high school they usually find that there are no formal care options available.

It is in this childcare context that informal carers (in the context of a mixed childcare package) play a crucial role in assisting single parents to enter employment and to sustain it. Informal carers supplement formal care by smoothening transitions associated with changing childcare needs, assisting mothers with childcare crises, and stepping in to assist with some of the juggling associated with managing work and care work on an on-going day-to-day basis (Brady 2016). Thus, in a mixed care package informal care supplements rather than replaces formal care. In the conclusion of this chapter I argue that these findings suggest that there is a need for the formal childcare system to be more flexible and supportive of mothers' and children's changing childcare needs.

The structure of this chapter is as follows: (1) the current literature on single parents' lifecourses, childcare and employment, and on QL methodologies is reviewed; (2) the Australian work and family policy context is described; (3) the study, including the data and analysis, is described; and (4) I illustrate how single mothers' use of mixed childcare packages shapes their entry into employment/ study, their ability to balance paid employment/study and caring commitments once they enter paid employment/study, and their ability to manage shifting childcare needs across the lifecourse. 


\section{Single Parents' Lifecourses and Childcare and Employment}

Existing research finds that single mothers have diverse employment trajectories with some experiencing long periods without employment, others cycling in and out of employment (and on and off income support), and yet others maintaining fulltime employment with few breaks (Barrett and Cobb-Clark 2001; Barrett 2002; Zagel 2013). A single mother's ability to enter employment and maintain it is dependent on her ability to find appropriate alternative carers during the periods she is working (Brady 2010; Cabrera et al. 2013; Scott et al. 2005). Making care arrangements is not a one-off activity but instead once single mothers gain employment they must assimilate this activity with "caring for their children on an ongoing basis, sustained over time" (Millar and Ridge 2009, p. 104). In the United States researchers find that when single mothers who are financially dependent on Temporary Assistance to Needy Families (TANF) move into paid work, they are commonly forced to depend on unstable patchworks of care. This reliance on informal care is due to financial constraints (including lack of access to subsidies for formal childcare), and the low supply of formal care in low income areas (Scott et al. 2005). The unreliability of their care is due to the unpredictability of informal carers over time (Fuller et al. 1996; Scott et al. 2005) with family not always following through on commitments (Fuller et al. 1996). Research also concludes that these childcare difficulties are the key factors that causes single mothers to return to TANF (Anderson et al. 2004).

Due to this unreliability of informal childcare, and its association with poorer child outcomes (particularly for children from disadvantaged backgrounds (Del Boca et al. 2014)); scholars in the UK, US, Australia and elsewhere have advocated for the provision of affordable, high quality formal childcare for single mothers who are moving from "welfare to work" (Brady and Cook 2015). At the same time these scholars recognise the importance of social support in enabling single mothers to sustain employment (Mason 2003; Ridge and Millar 2011; Scott et al. 2005). In the UK Millar and Ridge (2009) argue that social relationships across work, home, school and care settings "may be a key element in employment sustainability" (p. 104), while a review of the literature on single mothers and social support by Cook (2012) argues that families and friends may provide crucial free transport, food, and childcare that help mothers combine work and care.

As I elaborate in more detail below what is missing from this literature is a consideration of the experiences of single mothers who use formal and informal childcare concurrently (i.e. mixed childcare packages). As I have argued elsewhere (Brady and Perales 2016), this is problematic insofar as single mothers who use mixed childcare on average work significantly longer hours compared to mothers who use other childcare packages (after controlling for demographic factors and hours of childcare used). Although McKie et al. (2002) have made a compelling case for examining the temporal dimension of balancing work and care, to date the dynamics of single mothers' experiences of balancing work and care have been underexplored. Elsewhere I have focused on conceptualizing the key roles played 
by informal carers over time (Brady 2016). In contrast this chapter draws on lifecourse concepts to systematically examine how single mothers' use of mixed childcare packages shapes their employment trajectories over time.

\section{Qualitative Longitudinal Research: Fateful Moments, Timespaces and Caringscapes}

QL research is increasingly being used to understand multiple dimensions of key lifecourse transitions including "welfare to work", or "school to work" (Holland and Thomson 2009; Lewis 2007; Thomson et al. 2002). As addressed in other chapters, lifecourse studies focus primarily on the timing, duration, and cessation (or desistance); as well as order, sequencing, and occurrence of life transitions, life events and trajectories and the relationships (or interlock) between earlier and subsequent life course transitions and trajectories (Macmillan and Copher 2005). Within the lifecourse literature trajectories are defined as "life course dynamics that take place over an extended period of time" and as starting and ending with a transition (Macmillan and Copher 2005, p. 5; Mayer and Settersten 1997). Transitions are embedded within trajectories and are concerned with how people move from one "role to another, begin or cease a course of activity, experience a particular state, or stop doing so"(Macmillan and Copher 2005, p. 5). Furthermore, in contrast to an 'event', transitions are "conceptualized as a more gradual change" (Mayer and Settersten 1997, p. 252).

In the area of work, family and social policy lifecourse research has been overwhelmingly quantitative but the number of QL studies has grown significantly over the last decade (Holland and Thomson 2009; Millar and Ridge 2009; Thomson 2007). QL research makes an important contribution to the lifecourse literature because it enables a focus on dimensions and experiences of time and change that are not possible in quantitative research. Although QL research has in common with quantitative approaches a focus on transitions, it diverges from quantitative approaches in that it seeks to illuminate the perceptions of the individuals involved (Millar and Ridge 2009; Thomson et al. 2002). A particular focus has developed around critical moments or fateful moments, "times when events come together in such a way that an individual stands, as it were, at a crossroads in his existence" these include things such as the "deciding to opt for a particular apprenticeship or course of study" or "giving up one job in favour of another" (Giddens 1991, pp. 112-3; Holland and Thomson 2009; Thomson et al. 2002).

QL research also has the potential to add to the lifecourse literature through a focus on the multiplicity of time, though to date this potential has largely not been exploited. For instance, McKie et al.'s (2002) work has drawn attention to the spatial and temporal dimensions of combining paid work and care. Their work builds on Adam's (2000) notion of timescapes, and its associated argument that we should supplement quantitative time (calendars and clocks) with recognition of context (time and space), and the multidimensionality of time (different functions of time). Building on this notion of timescapes McKie et al. (2002) argue that there is a need 
to pay greater attention to the experience of combining paid work and care across the lifecourse. Within their discussion of caringscapes - "imagining the spatial-temporal nature of everyday life" (p. 918) - they argue we need to pay greater attention to the temporal dimensions of the experience of combining caring and working including:

planning, worrying, anticipating, speculating prioritizing, assessing the quality of care, accessing care, controlling care, paying for care, shifting patterns of work, job (in) security, the potential for promotion, moving home, managing family sources, supporting school work, being involved in the school or care group and so on (p. 915).

In summary then, current QL research extends the quantitative lifecourse literature's focus on the timing or sequencing of life transitions, events and trajectories to examine subjective experiences of transitions, and the specific time and context. Within the research area of work, family and social policy the QL approach also has the potential to highlight how socially embedded individuals experience changing work and care arrangements, needs and tensions.

\section{Australian Context: Single Parenthood, Income Support and Childcare}

Single parents' experiences of entering employment and combining work and care on an on-going basis is strongly shaped by the national context. Some important factors that shape this experience include the prevalence of single parent families, the specifics of childcare/early education systems, the nature of policies around income support for single parents, employees' entitlements, and cultural attitudes to early childhood care (Mamolo et al. 2011; Marchbank 2004).

In June 2012, 22\% of all families with dependents in Australia were one parent families (ABS 2013). One parent families with dependents are defined in official statistics as a "person who is not in a couple relationship with anyone usually resident in the same household", but has at least one child usually resident in the household who is aged under 15 years or a dependent student aged 15-24 years who is "attending school or studying full-time at a tertiary education institution" (ABS 2013). A little over half (52\%) of single mother families with dependants (0-14) were employed and employment rates were much lower for those with younger children (ABS 2013).

Australia is usually classified as a liberal welfare regime, but it has also been classed as a wage earners' (or antipodean) welfare regime (Castles and Mitchell 1990; Castles 1994; Mitchell 1998). Wage earners' welfare regimes have in common with liberal welfare regimes a focus on targeting income support at those with low incomes and assets and a preference for largely leaving childcare and elder care to families, charities, the market, and compulsory schooling (Esping-Andersen 2012; Kilkey 2000). However, unlike liberal welfare regimes, they also promote worker's well-being through relatively strong regulation of working conditions and wages. Casual and part-time workers in Australia therefore benefit from somewhat better wages and conditions compared to workers employed under these contracts in other jurisdictions. 
Overall, Australia's policies around income support for single parents, and early childhood education and care (ECEC), are largely consistent with the tendencies associated with liberal and antipodean welfare regimes. Since 2002 the Australian government has applied compulsory activity requirements to claimants of PPS who had a school aged child. New policies implemented over the last decade have progressively increased the intensity of the activity requirements that are applied to this group. In the week prior to the commencement of data collection for this study the government announced new activity requirements. Australian single parents with a child aged less than 8 years would be allowed to continue to claim PPS and would not be obliged to engage in paid work or education/training. However, those with a child aged over 7 years would be moved to an unemployment payment (Newstart allowance), which is paid at a lower rate than PPS, and they would be obliged to seek at least $15 \mathrm{~h}$ of paid work (per week). However, those who were already claiming PPS when the changes were announced were exempted from the requirement to move to Newstart. Thus some of my interviewees were subject to the new activity requirements but none were moved to Newstart payment during the course of my study.

Consistent with its classification as a liberal or antipodean welfare regime, nonparental care for children under school age ${ }^{2}$ is most commonly provided by relatives (usually grandparents), for-profit childcare centres, and to a lesser degree not-forprofit organizations and family day-care (child-minders) (Australian Bureau of Statistics 2012; Baxter et al. 2007). A little over half (55\%) of all children aged 0-4 attend childcare, and of these $40 \%$ only use formal childcare, a quarter (26\%) only use informal childcare, and a third (32\%) attend both formal and informal care (Australian Bureau of Statistics 2012). Patterns of childcare use amongst employed single mothers with young children largely reflect these broader patterns with a third (33\%) using formal only, a little over a quarter (28\%) using informal only, and a little over a third (37\%) using both formal and informal care (mixed childcare) (Brady and Perales 2016). ${ }^{3}$ These patterns of childcare use are also very similar to those observed in other liberal welfare regimes including the US and UK (Emlen 2010; Hansen et al. 2006; Rutter and Evans 2011).

While the broad patterns of childcare use in Australia are similar to other liberal welfare regimes its approach to ECEC deviates from a typical liberal regime in some significant respects. One importance deviation is Australia's emphasis on tightly regulating the quality of childcare via the Australian Federal Government's National Quality Framework (Brennan and Adamson 2014; Mahon et al. 2012). A second important difference is that unlike the UK, Canada, and the United States; Australia has a national, income-tested childcare subsidy scheme (Childcare Benefit) and a non-income tested childcare rebate (Brennan and Adamson 2014). For the vast majority (95\%) of families, government subsidies cover at least $50 \%$ of

\footnotetext{
${ }^{2}$ The age at which compulsory full-time schooling commences varies from state to state, ranging from 4 years and 7 months, to 5 years.

${ }^{3}$ Formal childcare is defined as care purchased via the market and includes family-based day-care, centre-based care and nannies. Informal childcare is care provided by neighbours, family members and friends. Mixed care refers to childcare packages that involve concurrent use of formal and informal care.
} 
their childcare fees (Australian Government. Productivity Commission [P.C.] 2014, p. 383). As a result of these government subsidies the childcare costs of low income ${ }^{4}$ single parents in Australia are lower than those of single parents living in many other Anglophone countries (except for the UK). However, low income Australian single parents still experience substantially higher childcare costs than single parents living in Demark, Sweden or France (OECD 2014). Thus, while the average cost of childcare (after the subsidy) is substantially lower than in many other Anglophone countries, Australian parents seeking toddler and infant care still face high costs (Mahon et al. 2012).

In the last decade on-going criticism of the relatively high cost of childcare in Australia has been joined by new criticisms regarding its inflexibility and inadequacy for addressing the reality of Australia's 24/7 economy (Brennan and Adamson 2014; P.C. 2014). This criticism stems from the nature of Australia's childcare subsidy system. Most subsidized forms of childcare are relatively inflexible, whereas more flexible forms of childcare are difficult to access because places in these services are either tightly capped or not subsidized. Specifically, while parents who use registered childcare centres and registered family daycare can access government subsidies many of these services do not meet the needs of the large number of parents who work non-standard hours (Brennan and Adamson 2014; Craig and Powell 2011).The usual operating hours of childcare centres and family daycare is 7:30/8 am to $6 \mathrm{pm}$ and families are generally required to book a regular day of care and not allowed to change these from week to week, though some family daycare educators do offer care outside of standard centre hours ( $7 \mathrm{am}$ to $6 \mathrm{pm}$ ) and are more flexible about changing the days of care (Brennan and Adamson 2014).The only service specifically designed to meet the needs of parents who work non-standard hours is the Australian Government's In Home Care program which allows single and partnered parents, whose work shifts include hours during which no approved childcare service operates, to apply for access to subsidized in-home care (Australian Government: Department of Education 2012). However, not all eligible parents can access this program because the number of places is capped (Brennan and Adamson 2014). Within this social and policy environment informal carers, in the context of a mixed childcare package, play a critical role in helping single mothers to enter and sustain employment.

\section{The Study}

\section{Data Collection}

The findings presented in this chapter are based on interview data from a 3 year longitudinal qualitative study with 30 single mothers. At the time of the first interview all these mothers had at least one child aged less than 7 years, were living in Perth, Western Australia, and were in receipt of Parenting Payment, which is an

${ }^{4}$ Earning $50 \%$ of the average wage. 
income support payment for single parents. ${ }^{5}$ Each mother participated in an annual interview lasting 50-90 min. Only one participant did not complete all three interviews. Half of the 30 single mothers in my study left income support during the 26 months of my research (a third due to re-partnering and two thirds due to being over the means test threshold as a result of their earnings from paid work). This is consistent with research that suggests that only $15 \%$ of single mothers in receipt of income support remain on payment continuously over a 4-year period (Barrett 2002; Gregory and Klug 2003).

Although each interview had a slightly different focus, all of the interviews explored the women's experiences of income support receipt, activation programs, participation in employment/study and use of childcare. ${ }^{6}$ The sampling strategy sought to select a group of women who captured the diversity amongst the population of single mothers with young children who are in receipt of income support. Potential participants were recruited using multiple strategies including attendance at a teenage mother's group, university press releases, an interview on local radio, the placement of posters in places commonly frequented by single parents (including shopping centres, medical clinics, indigenous women's health centres, childcare centres, and libraries), and finally placement of messages on single mother/parent e-lists and parenting web-boards.

\section{The Sample}

Interviewees' ages and number of children largely reflected the population of single mothers with young children. Interviewees were aged between 20 and 41 years, and had an average of 1.5 children. Most (two thirds) had only one child, while $13 \%$ had three children, and $20 \%$ had two. The sample was evenly split between those who had very young children (new-born to 3 years) and those who had an older youngest child (aged 4 to almost 7 years).

Mothers were similarly diverse in terms of their educational attainment, labour force status, and childcare packages. One third of interviewees had obtained a Bachelor degree (or higher) but slightly more (40\%) had not completed high school.

\footnotetext{
${ }^{5}$ At the time of the first interview Parenting Payment (single) was available to all primary carers of a child aged less than 16 years who met strict income and assets tests. For full details of how the income and assets test of parents are taken into account when determining eligibility for Parenting Payment see Australian Government: Centrelink (2005). This booklet also outlines the associated allowances and payments these parents receive include concession cards, a pharmaceutical allowance, Family Tax benefit and a range of other small benefits.

${ }^{6}$ In terms of income support policies, the single mothers that are the subject of this article were required to seek $15 \mathrm{~h}$ of paid work per week once their youngest child turned 8 years old (Grahame and Marston 2012) However, if registered formal childcare was not available, or travel time was excessive, or if the parent would not benefit financially from the paid work they were not obliged to accept the employment offer.
} 
Comparison with population figures reveals that single mothers who have a degree are over-represented in the study while single mothers who have completed high school but have no further education are under-represented (ABS 2008). The employment rate amongst the sample also appeared to be slightly higher than the broader population of single mothers with half of the interviewees reporting participation in some form of employment at the time of the first interview (ABS 2008). Given that eligibility for income support (Parenting Payment) is subject to income tests, it is not surprising that only two interviewees were employed full-time at the time of the first interview, while the remainder were working part-time on either a permanent or casual basis. In terms of childcare packages, at the time of the first interview interviewees commonly used mixed childcare packages (13 out of 30). Parental only care $(n=8)$, formal only $(n=6)$, and informal only $(n=3)$ were less common packages of care.

The analysis takes differences between interviewees' characteristics and the characteristics of the broader population by examining how a whole range of individual characteristics and institutional constraints work together in particular cases, rather than attempting to generalize in a straightforward way from the frequencies in the sample to the population.

\section{Data Analysis}

Interviews were fully transcribed before being analysed using Spencer and Ritchie's 'Framework' approach to inductive thematic analysis with NVivo 10. The Framework approach involves creating summaries of the individual themes for each case (interviewee). This involved: (1) immersion in the data through close reading of the interview transcripts; (2) developing the coding index through identifying the themes related to interviewees' experiences of employment that would form the Framework; (3) coding the data in NVivo 10 by systematically applying the coding index to the transcripts; (4) charting: creation of a 'Framework Matrix' in NVivo 10, with thematic headings and summaries of these themes for each case in order to "build up a picture of the data as a whole"(Ritchie and Spencer 2002, p. 317); and (5) mapping and interpretation: where the researcher "searches for patterns and connections" across the themes "and seeks explanations for these internally within the data" (Ritchie and Spencer 2002, p. 321).

Drawing on McKie et al.'s (2002, p. 910) concept of caringscapes I focused on themes related to the dynamics of experiences of care over time, and "the significance of the time and space-bound social relations inherent in the existence of locales". Furthermore, drawing on the lifecourse approach I focused on key transitions and turning points: (1) entering employment; (2) balancing work and care day to day; and (3) changing childcare needs across the lifecourse. Once it was clear that informal carers played a key role in helping single mothers to move into employment and sustain it over time, I then sought to identify individual case studies that illustrated "contrasting dynamics" (Shirani and Henwood 2011). This chapter 
primarily focuses on specific cases that illustrate how these broader patterns of difference played out. That is, while the chapter makes reference to the patterns that were evidenced across the sample of 30 mothers; in the presentation of findings I primarily focus on specific cases so as to illuminate "the complexities of "individual" families', and the "significance of the time and space-bound social relations inherent in the existence of locales"(McKie et al. 2002, p. 910).

\section{The Role of Informal Carers in Supporting Single Mothers' Transition from "Welfare to Work"}

Current childcare policy largely "does not incorporate an awareness of the demands of the everyday across the lifecourse" (McKie et al. 2002, p. 897). The result is that most single mothers who are employed struggle to make work and care align over the long term. Millar and Ridge's (2009) recent research on single mothers leaving income support highlights the important role that social relations play in enabling them to achieve employment sustainability. Specifically, their findings highlight the important role that social relations within (and outside) the family play in helping them maintain employment over time (Millar and Ridge 2009). This chapter elaborates on their findings by arguing that for women with young children a very specific form of social support, namely informal childcare from friends or relatives, in the context of a mixed childcare package, is crucial for enabling them to achieve strong employment trajectories.

My comparison of cases over time revealed that the relationship between the type of childcare package that a mother used and her employment trajectory emerged from the differential abilities of these packages to bring together, in space and time, the different locations within which childcare and paid work occurred (McKie et al. 2002). Interviewees who relied entirely on formal childcare (centre-based or family daycare), or entirely on informal childcare, experienced greater struggles with moving beyond low part-time hours, or transitioning into higher quality employment, compared to interviewees with similar characteristics who used mixed childcare packages. In the following it is argued that many of the difficulties experienced by those using only formal care emerged from difficulties with finding care that adapted to children's and parent's changing needs, and which fitted with their employment circumstances. Single mothers who used mixed childcare packages (formal childcare and informal care concurrently) experienced much stronger employment trajectories as a result of (1) a greater ability to obtain suitable care as soon as they received an offer of employment or started a new program of study; (2) a greater capacity to balance work and care on an on-going basis; and (3) an ability to fall back on informal care when their children's needs or their employment arrangements changed, thereby rendering formal arrangements no longer suitable. 


\section{Entering Employment or Education, and the 'Helping Hand' of Informal Care}

A single mother's entry into employment is contingent upon finding childcare that matches her work hours. Typically she must commence work soon after an employment offer is made, but locating a formal childcare placement for the required hours/ days commonly takes weeks or months. The presence of kin (or friends) who are willing to provide childcare until she can find a suitable formal childcare place may thus be critical to her successful transition into paid work. A typical example of this kind of experience was that of Sandra who worked as a part-time lecturer on short, fixed-term contracts. Sandra finished her $\mathrm{PhD}$ shortly before the birth of her first child and when her daughter was 4 months old she was offered a position as a parttime lecturer but was unable to find a place at local daycare centres. Sandra explained:

I mean in the first semester I worked I couldn't get [Rose] into a daycare so she had to go to family and it was only that second semester that they [the childcare centre] gave me a half a day a week; that is all they could give, and I just had to keep taking her in for half a day so that I could get the days I needed.

[ ] = added text

By the time of the second interview, Sandra had increased her work hours and was working full-time across three separate part-time appointments; and as I discuss below, her mixed childcare package also assisted her with the challenge of balancing work and care on an on-going basis.

Given the reality of long waiting lists for most childcare centres, single mothers may not be able to accept an offer of employment if they do not have kin who can provide short term care until they locate a place in formal childcare. Linda's experience was an illustrative example of this problem. At the time of the first interview, Linda had very recently separated from her husband, and she had primary custody of their three children (aged 4-13 years). She had comparatively low labour market capital because she had engaged in little paid work since the birth of her first child 13 years prior. Her ability to access informal care was highly limited due to her social isolation. Her separation with her ex-husband was acrimonious with the result that no regular care arrangements could be negotiated with him over the 3 years of my study. Furthermore, all her immediate family lived in another state and while Linda had acquaintances through her children's activities, she had few close friends. Despite these multiple barriers to paid work, by the time of the second interview she had obtained three regular casual shifts as a waitress. All the shifts involved working 1 or 2 hours outside school hours, and during these periods she relied on her oldest child to care for the two younger siblings. Linda was keen to obtain employment with better pay and conditions, and in the period between the first and second interview, she applied for and was offered a full-time secretarial position with better pay. Unable to find before and after school care at short notice, Linda again relied on the oldest child to care for his siblings. However, this time he was responsible for helping get them ready for school and heating up dinner five times a week. During her 1 week trial of her new job Linda decided that (in her own 
words) "it just wasn't workable." She quit and returned to her low paid waitressing position. We may view this as being a "critical moment" (Giddens 1991, pp. 112-3; Holland and Thomson 2009; Thomson et al. 2002) for Linda where things came together in a way that she had to make a decision that would significantly shape her employment trajectory over the medium term. In this case Linda's inability to find suitable childcare at short notice amplified the stress associated with returning to full-time work while continuing to caring for three children. Although the lack of informal support with childcare was not the single factor that determined her decision, it is clear this absence reduced her ability to take up this new position.

\section{Balancing Work/Study and Care}

Single mothers' abilities to balance work and care, or formal study and care, on an on-going basis was shaped by a number of factors; including their personal feelings about the appropriateness of using non-parental care for young children, their work/ study schedules, and their childcare package. Sandra, whose story of entering employment following her daughter Rose's birth was outlined earlier, continued to use mixed care in the second year of my study. She explained Rose's childcare schedule as follows:

On Monday she stays with her dad's mum. Tuesdays she's at daycare all day. Wednesday morning she's at daycare, then she's with her dad in the afternoon. And Thursday all day she's been at daycare just because [this year] my parents are doing the grey-haired nomad thing, and travelling around Australia in a caravan. And on Fridays she's been at her dad's mother's.

$$
\text { [ ] = added text }
$$

When I asked why she used this care option she explained, "Well, daycare is expensive" but also she explained that she was unwilling to place Rose in formal childcare for more than 2 days a week. Thus, when I asked Sandra, "What would you do in terms of work, paid work, if you didn't have the help from your family?" She replied:

I don't know, you know. I think I'd be quite stuck....sometimes I wish I wasn't a solo parent. But, other times I think I've got it a lot luckier than other women that I know, who don't have that support network. And, don't have a father who's interested in fathering the child, you know. Like I really feel like that [not having support from family] would be really hard.

[ ] = added text

One of the common cause of clashes between paid work and care obligations is unpredictable work-schedules, and working non-standard hours. Consistent with this, interviewees with these work schedules experienced more challenges in balancing work/study and care on an on-going basis. Consistent with existing research (Williams et al. 2013), highly educated interviewees in professional employment usually had predictable work schedules, worked within standard business hours, and when they did work non-standard hours they had some flexibility in their schedule. As Nina, a technologist at a major hospital, explained, "I've had to...change my 
shift at [hospital name] from an evening shift to a day shift ...I just swap ...there is a few people." Interviewees with low education in non-professional employment in contrast experienced what I call erratic rigidity. Not only did they commonly have to work outside standard business hours, and have schedules that changed from week to week, they also usually had very little ability to influence the schedules they were assigned (Williams et al. 2013). For interviewees who used mixed care, the challenges associated with these kinds of schedules were significantly reduced. An illustrative example is the experience of Julie, who commenced full-time employment as an events manager between interviews one and two, and who had three children, including a daughter who was only 6 months old at the time of the first interview. Julie explained that she had to work until an event finished which meant that:

at least once a week [I work late at night], sometimes twice, not usually until two, but usually twice a week until 10.30 till $11 \ldots$ So I work nights, I work weekends.

Such experiences are common among Australian single mothers with almost half (45\%) reporting they have no say in their start and finish times (ABS 2009). Employed single mothers' concentration in non-professional employment in part reflects the relatively low average level of education amongst this population (ABS 2008). ${ }^{7}$ In Julie's case her use of a mixed childcare package helped her to balance work and care. Her package included centre-based care for her infant daughter, and after-school care for her sons during the week, while most of the weekend they stayed with their father (Thursday, Friday and Saturday night). Julie explained at interview two that she had relied a lot on her family to balance work and care after she had taken up her position as an events manager, because she had not realised "how much night work and weekend it [her job] was going to take". For a period of a few months she relied on her mother to care for her infant daughter, and also on her wide network of close friends. In the longer term this heavy, on-going reliance on family and friends was not sustainable and Julie eventually obtained in-home care. However, in the medium term, her family and friends provided essential assistance with balancing work and care.

\section{Managing Changing Childcare Needs Across the Lifecourse}

Children's childcare needs change rapidly as they grow "and, as careers/jobs change, so do the needs of parents" (p. 910). However, as McKie et al. (2002) have argued, this obvious point is largely ignored by national childcare strategies and government funded programs and services which overwhelmingly "concentrate on younger children and ignore lifecourse changes" (p. 910). The highly dynamic nature of children's and single parents' childcare needs was evident across the 3 years of my study.

\footnotetext{
${ }^{7}$ Two in five Australian single mothers have not completed high school, and only $15 \%$ have a degree or higher.
} 
Children grew, their needs changed, and thus they needed new childcare arrangements. As one mother put it when I asked if her daughter was still attending family daycare now that she had started school, "My daughter out-grew family day-care." These kinds of changes were very common and almost all the mothers who used formal childcare reported at least one instance of their child 'out-growing' or suddenly forming a dislike for their formal childcare. In some instances, this apathy arose when the child was moved to a new childcare centre or when they were moved up to a different room/age group within the same centre; whilst in other cases these problems appeared to be simply a consequence of the child growing older and developing new preferences. An illustrative case of the former problem was Sophie's experience of her toddler son [Caylen] refusing to attend childcare following his move to a new centre as a result of her moving to a new college. As Sophie explained:

\begin{abstract}
When I was going to [first college] they had an adjoining daycare centre. He loved it at first, he had a friend that he just loved and the care was better. But then I moved to a different college and he had to move to a different daycare he started having troubles...I got worried because he was objecting so strongly that there was a situation or something that was happening. I got worried about that. Maybe it was too strict, maybe they spoke to him in a way that made him feel bad...I really struggled with it, if I should keep doing that. It was really breaking my heart to leave him like that. It was awful.
\end{abstract}

Concerned that forcing Caylen to continue to attend would have a detrimental effect on him, Sophie reluctantly make the decision to drop out of college and to defer further study until Caylen was a bit older. Three years later Sophie decided to commence part-time studies. As the weekly class was scheduled in the evening (6:30 to 9:30 pm) she relied on her parents (primarily her mother) to provide care for Caylen. When I asked why she had not relied on her parents for care earlier, she reported that she was unwilling to ask them to provide that much care. The following year, when Caylen began pre-school, Sophie commenced part-time work (2-3 days a week) at a bookstore during school hours in addition to her part-time studies.

Rebecca's experience, in contrast, illuminates how access to informal carers in the context of a mixed childcare package helps support a stronger employment trajectory. When I first interviewed Rebecca, she was completing a Bachelor of Social Work, and had one daughter (Violet) who was 2 years of age. Rebecca frequently relied on her parents to care for Violet and also supplemented this with 2 days of care at a childcare centre. Thus when her daughter Violet starting objecting to attending childcare she relied on her parents until she could make alternative arrangements. As Rebecca explained at the second interview:

she [Violet] loved when she was in the baby room but when she was two and a half they bumped her up to the big kid's room and she didn't like it, she didn't get the same attachment to the teachers or the other kids. ......At the [centre-based] daycare Violet was crying not to go, not to be left here, and she wanted to go back to the baby room, and if one of those teachers came through the room during the day she would get upset.

Rebecca persevered with keeping Violet at the centre "for a couple of months because it was just a couple of days a week." However, when she "didn't change" then Rebecca's "mother looked after her [Violet] until [she] was able to find a home 
[family] day care." During this period Rebecca continued with her studies, and by the third interview she was working in a position related to her degree.

\section{Discussion and Conclusion}

Existing studies demonstrate the important role that access to high quality, affordable childcare (Scott et al. 2005), and social support (Cook 2012; Millar and Ridge 2013; Ridge and Millar 2011), plays in supporting this transition. However, many dimensions of the relationship between childcare and single mothers' engagement in paid work have been overlooked. Within this chapter I have drawn on the concepts of the lifecourse and caringscapes to analyse data from a QL study that sought to understand the work and care experiences of single mothers with young children who were in receipt of income support. This approach has allowed me to make some important contributions to the current literature on single mothers.

Firstly, by taking a lifecourse perspective and drawing on a longitudinal study, I have revealed the degree to which the childcare needs of single mothers and their children are dynamic. This has been largely ignored in the literature which tends to emphasize the need for single mothers to obtain high quality, affordable care at a point in time. The implicit assumption underpinning this approach is that obtaining childcare is a one-off event. However, within this chapter I have illustrated that obtaining childcare involves single mothers engaging in on-going work to find childcare in a context where children's needs change and so do parents', and formal childcare is quite inflexible.

Secondly, this chapter makes a significant contribution to the literature on single mothers' childcare needs. To date the literature has emphasised these mothers' needs for affordable and high-quality care (Brady 2010; Cabrera et al. 2013; Scott et al. 2005). The findings presented here suggest that we also need to consider the issue of childcare inflexibility. While the problem of inflexibility has been briefly mentioned in the literature on mother's use of informal carers (Backett-Milburn et al. 2008; Millar and Ridge 2009), the literature has not sought to systematically identify the particular areas in which current childcare systems are inflexible.

This chapter suggests that there are four key ways that the current formal childcare system in Australia (and likely elsewhere) inhibits single mothers seeking to complete education or move into paid work, and to maintain a strong employment trajectory over time. Firstly, long waiting lists for formal care, particularly for very young children, frequently prevent single mothers from locating suitable childcare when they receive an employment offer or commence a new semester of study. The result is that while those who have family or friends available and willing to provide care may turn to them to provide "stop gap" care until a formal care place can be located, mothers who do not have this assistance will most likely have to decline the employment offer or withdraw from their study.

Secondly, the sharp age segmentation within current childcare services forces families to find different carers for children of different ages, and to change carers 
every few years as their children grow. Single mothers who had multiple children and access to informal carers commonly obtained their assistance with picking up (or dropping off) children at multiple locations. Mothers with multiple children who lacked access to informal care commonly struggled.

Thirdly, there are few formal childcare options available when single parents require emergency care because their usual arrangements have fallen apart. Informal carers may play a critical role in helping single mothers to adjust to these changing circumstances. A fourth and final dimension of inflexibility is the significant shortage of formal childcare options for single parents working non-standard hours. Currently there are very few twenty four hour childcare centres, and the In Home Care program is poorly advertised and also has limited places (Brennan and Adamson 2014).

What, then, are the practical implications of these findings? The first is the need for much more sustained attention to the problem of childcare flexibility. Existing statistical studies (Baxter et al. 2007; Brady and Perales 2016), and the analysis in this chapter, find that single parents who use mixed childcare have greater labour market success; because a mixed childcare package is more flexible than formalonly or informal-only childcare. In other words, the current childcare system makes it hard for single mothers who cannot access mixed childcare to succeed in the labour market. There is a need to develop a more flexible system that enables parents who have a personal preference for mixed care to continue to use this childcare package, but which does not disadvantage single mothers who cannot access a mixed childcare package. In Australia the issue of childcare flexibility is just starting to gain more attention from policy makers. In 2013 the Labor Government launched the 'Childcare Flexibility Trials' to trial more flexible care options, but the evaluation found that take-up of the trialled options was very low (Baxter and Hand 2016). A year later (2014) the new Coalition Government asked the Australian Productivity Commission to conduct an inquiry into childcare, and one of the six terms of reference specifically focused on options to improve flexibility (P.C. 2014). However, the pilot of subsidized nannies that was recommended by the commission has also struggled with poor take up (NewsABC 2016). This chapter suggests that further research is needed to more fully understand how the formal childcare system can be made more flexible, so as to address single mothers' needs when combining caring and paid work across the lifecourse. Such reforms are necessary to move beyond viewing the issue of work-life balance in terms of individual solutions (Brady 2008).

Acknowledgements I would like to thank participants at the Lone Parenthood in a Life Course Perspective workshop, 6th-7th June 2014 - University of Lausanne, and the two anonymous referees, for constructive feedback on earlier versions of this chapter. The field research upon which this chapter is based was supported by funding from a Provost Doctoral Entrance Award and a Department of Sociology Doctoral Research Grant, both from the University of Alberta.

This paper benefited from the support of the Swiss National Centre of Competence in Research LIVES - Overcoming Vulnerability: Life Course Perspectives, which is financed by the Swiss National Science Foundation (Grant number: 51NF40-160590). 


\section{References}

Adam, B. (2000). The temporal gaze: The challenge for social theory in the context of GM food. The British Journal of Sociology, 51(1), 125-142.

Anderson, S. G., Halter, A. P., \& Gryzlak, B. M. (2004). Difficulties after leaving TANF: Inner-city women talk about reasons for returning to welfare. Social Work, 49(2), 185-194.

Australian Bureau of Statistics. (2008). 4102.0 - Australian social trends, 2007. Canberra: Australian Government.

Australian Bureau of Statistics. (2009). 4102.0 - Australian social trends. Canberra: Australian Government.

Australian Bureau of Statistics. (2012). Childhood education and care, Australia, June 2011. Canberra: Australian Government.

Australian Bureau of Statistics. (2013). 6224.0.55.001 - Labour force, Australia: Labour force status and other characteristics of families, June 2012. Canberra: Australian Government.

Australian Government: Centrelink. (2005). A guide to Australian Government payments: On behalf of the Department of Families and Community Services and Indigenous Affairs, the Department of Education, Science and Training, and the Department of Employment and Workplace Relations - 20 September-31 Dec 2005. Canberra: Australian Government.

Australian Government: Department of Education. (2012). In home care eligibility. Canberra: Australian Government. Retrieved 2012 from https://docs.education.gov.au/documents/ home-care-eligibility-checklist

Australian Government: Productivity Commission [P.C.]. (2014). Childcare and early childhood learning: Productivity commission draft report. Canberra: Commonwealth of Australia.

Backett-Milburn, K., Airey, L., McKie, L., \& Hogg, G. (2008). Family comes first or open all hours?: How low paid women working in food retailing manage webs of obligation at home and work. The Sociological Review, 56(3), 474-496.

Barrett, G. F. (2002). The dynamics of participation in the sole parent pension. Economic Record, 78(240), 1-17.

Barrett, G., \& Cobb-Clark, D. (2001). The labour market plans of parenting payment recipients: Information from a randomised social experiment. Australian Journal of Labour Economics, 4(3), 192-205.

Baxter, J. A., \& Hand, K. (2016). Flexible child care: Key findings from the AIFS evaluation of the child care flexibility trials. Melbourne: Australian Institute of Family Studies.

Baxter, J., Gray, M., Alexander, M., Strazdins, L., \& Bittman, M. (2007). Mothers and fathers with young children: Paid employment, caring and wellbeing. Canberra: FaHCSIA.

Brady, M. (2008). Absences and silences in the production of work-life balance policies in Canada. Studies in Political Economy, 81, 99-128.

Brady, M. (2010). Understanding single mothers' choices around paid work and education: Preference theory versus a practices of mothering framework. Public Policy, 5(1), 23.

Brady, M. (2016). Gluing, catching and connecting: How informal childcare strengthens single mothers' employment trajectories. Work, Employment \& Society, 30(5), 821-837.

Brady, M., \& Cook, K. (2015). The impact of welfare to work on parents and their children. Evidence Base, 2015(3), 1-23.

Brady, M., \& Perales, F. (2016). Hours of paid work among single and partnered mothers in Australia: How childcare package matters. Journal of Family Issues, 37(3), 321-343.

Brennan, D., \& Adamson, E. (2014). Financing the future: An equitable and sustainable approach to early childhood education and care. SPRC Report, 1, 14.

Cabrera, N., Hutchens, R., \& Peters, H. E. (2013). From welfare to childcare: What happens to young children when mothers exchange welfare for work? New Jersey/London: Lawrence Erlbaum Associates.

Castles, F. G. (1994). The wage earners welfare state revisited. The Australian Journal of Social Issues, 29(2), 120-145. 
Castles, F. G., \& Mitchell, D. (1990). Three worlds of welfare capitalism or four? Australian National University, Graduate Program in Public Policy.

Cook, K. E. (2012). Social support in single parents' transition from welfare to work: Analysis of qualitative findings1. International Journal of Social Welfare, 21(4), 338-350.

Craig, L., \& Powell, A. (2011). Non-standard work schedules, work-family balance and the gendered division of childcare. Work, Employment \& Society, 25(2), 274-291.

Del Boca, D., Piazzalunga, D., \& Pronzato, C. (2014). Early child care and child outcomes: The role of grandparents (IZA Discussion Paper).

Emlen, A. (2010). Solving the childcare and flexibility puzzle: How working parents make the best feasible choices and what that means for public policy. Boca Raton: Universal Publishers.

Esping-Andersen, G. (2012). The three worlds of welfare capitalism. Cambridge: Polity Press.

Fuller, B., Holloway, S. D., Rambaud, M., \& Eggers-Pierola, C. (1996). How do mothers choose child care? Alternative cultural models in poor neighborhoods. Sociology of Education, 69, 83-104.

Giddens, A. (1991). Modernity and self-identity. Cambridge: Polity Press.

Grahame, T., \& Marston, G. (2012). Welfare-to-work policies and the experience of employed single mothers on income support in Australia: Where are the benefits? Australian Social Work, 75(1), 73-86.

Gregory, R. G. and E. Klug. (2003). A Picture Book Primer: Welfare Dependency and the dynamics of female lone parent spells (mimeo). Economics, Research School of Social Science. Australia: Australian National University.

Hansen, K., Joshi, H., \& Verropoulou, G. (2006). Childcare and mothers' employment: Approaching the millennium. National Institute Economic Review, 195(1), 84-102.

Haux, T. (2012). Activating lone parents: An evidence-based policy appraisal of welfare-to-work reform in Britain. Social Policy and Society, 11(01), 1-14.

Haux, T. (2013). Lone parents and activation-towards a typology of approaches. Journal of International and Comparative Social Policy, 29(2), 122-133.

Holland, J., \& Thomson, R. (2009). Gaining perspective on choice and fate: Revisiting critical moments. European Societies, 11(3), 451-469.

Kilkey, M. (2000). Lone mothers between paid work and care : The policy regime in twenty countries. Aldershot/Burlington: Ashgate.

Knijn, T., Martin, C., \& Millar, J. (2007). Activation as a common framework for social policies towards lone parents. Social Policy \& Administration, 41(6), 638-652.

Lewis, J. (2007). Analysing qualitative longitudinal research in evaluations. Social Policy and Society, 6(04), 545-556.

Macmillan, R., \& Copher, R. (2005). Families in the life course: Interdependency of roles, role configurations, and pathways. Journal of Marriage and Family, 67(4), 858-879.

Mahon, R., Anttonen, A., Bergqvist, C., Brennan, D., \& Hobson, B. (2012). Convergent care regimes? Childcare arrangements in Australia, Canada, Finland and Sweden. Journal of European Social Policy, 22(4), 419-431.

Mamolo, M., Coppola, L., \& Di Cesare, M. (2011). Formal childcare use and household socioeconomic profile in France, Italy, Spain and UK. Population Review, 50(1), 170-194.

Marchbank, J. (2004). Women, power and policy: Comparative studies of childcare. New York: Routledge.

Mason, R. (2003). Listening to lone mothers: Paid work, family life, and childcare in Canada. Journal of Children and Poverty, 9(1), 41-54.

Mayer, K. U., \& Settersten, R. A. (1997). The measurement of age, age structuring, and the life course. Annual Review of Socioogy, 23, 233-261.

McKie, L., Gregory, S., \& Bowlby, S. (2002). Shadow times: The temporal and spatial frameworks and experiences of caring and working. Sociology, 36(4), 897-924.

Millar, J., \& Ridge, T. (2009). Relationships of care: Working lone mothers, their children and employment sustainability. Journal of Social Policy, 38(01), 103-121.

Millar, J., \& Ridge, T. (2013). Lone mothers and paid work: The 'family-work project'. International Review of Sociology, 23(3), 564-577. 
Mitchell, D. (1998). Life-course and labour market transitions: Alternatives to the breadwinner welfare state. In M. Gatens \& A. Mackinnon (Eds.), Gender and institutions: Welfare, work and citizenship (pp. 19-37). Melbourne: Cambridge University Press.

OECD. (2014). PF3.4 Childcare support. In OECD (Ed.), OECD family database. Paris: OECD.

Ridge, T., \& Millar, J. (2011). Following families: Working lone-mother families and their children. Social Policy \& Administration, 45(1), 85-97.

Ritchie, J., \& Spencer, L. (2002). Qualitative data analysis for applied policy research. In M. Huberman \& M. B. Miles (Eds.), The qualitative researcher's companion (pp. 305-329). Thousand Oaks: SAGE.

Rutter, J., \& Evans, B. (2011). Informal childcare: Choice or chance? London: Daycare Trust.

Scott, E. K., London, A. S., \& Hurst, A. (2005). Instability in patchworks of child care when moving from welfare to work. Journal of Marriage and Family, 67(2), 370-386.

Shirani, F., \& Henwood, K. (2011). Continuity and change in a qualitative longitudinal study of fatherhood: Relevance without responsibility. International Journal of Social Research Methodology, 14(1), 17-29.

Thomson, R. (2007). The qualitative longitudinal case history: Practical, methodological and ethical reflections. Social Policy and Society, 6(04), 571-582.

Thomson, R., Bell, R., Holland, J., Henderson, S., McGrellis, S., \& Sharpe, S. (2002). Critical moments: Choice, chance and opportunity in young people's narratives of transition. Sociology, 36(2), 335-354.

Williams, J. C., Blair-Loy, M., \& Berdahl, J. L. (2013). Cultural schemas, social class, and the flexibility stigma. Journal of Social Issues, 69(2), 209-234.

Winter, C. (2016). Nanny pilot program slashed in mid-year budget update due to low numbers of families signing up. NewsABC. Retrieved from http://www.abc.net.au/news/2016-12-20/ nanny-pilot-programme-slashed-in-mid-year-budget-update/8134104

Zagel, H. (2013). Are all single mothers the same? Evidence from British and West German women's employment trajectories. European Sociological Review, 30(1), 49-63.

Michelle Brady is a Senior Research Fellow in Sociology in the School of Social Science, University of Queensland. Prior to joining UQ in 2012 she worked as an Assistant Professor at the University of Victoria, Canada. Michelle received her PhD in Sociology in 2011 from the University of Alberta. Currently she is the lead Chief Investigator on an Australia Research Council Discovery project on childcare flexibility. She is also lead author on offical evaluations of Australia's first publically funded paternity leave scheme, and in-home childcare scheme. Her work has been published by the Journal of Social Policy, Work, Employment and Society, University of Toronto Press and Critical Policy Studies.

Open Access This chapter is licensed under the terms of the Creative Commons Attribution 4.0 International License (http://creativecommons.org/licenses/by/4.0/), which permits use, sharing, adaptation, distribution and reproduction in any medium or format, as long as you give appropriate credit to the original author(s) and the source, provide a link to the Creative Commons license and indicate if changes were made.

The images or other third party material in this chapter are included in the chapter's Creative Commons license, unless indicated otherwise in a credit line to the material. If material is not included in the chapter's Creative Commons license and your intended use is not permitted by statutory regulation or exceeds the permitted use, you will need to obtain permission directly from the copyright holder.

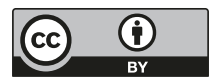

